American J. of Engineering and Applied Sciences 4 (2): 276-287, 2011

ISSN 1941-7020

(C) 2011 Science Publications

\title{
Developing a Computer Program for the Methods of Radius-Estimating Techniques for Horizontal Curves
}

\author{
${ }^{1}$ Asma Th. Ibraheem and ${ }^{2}$ Fatin Janan \\ ${ }^{1}$ Department of Civil Engineering, Nahrain University, \\ College of Engineering, Baghdad, Iraq \\ ${ }^{2}$ Department of Surveying Foundation of Technical Education, \\ Technical College, Baghdad, Iraq
}

\begin{abstract}
Problem statement: This study discusses the development of computer software of two phases. First phase contains the calculations of all curve elements of the four types of the horizontal curve and second phase contains the modeling of the ten methods of estimating the radius of the horizontal curve. Approach: The program is named as HCRET, which stands for Horizontal Curves and Radius Estimating Techniques. The program is written in Visual Basic-Version 6 language. The developed program deals with the calculation of all elements of the horizontal curve of the four types of the horizontal curves, which consists of simple, compound, reverse and transition. Results: The program also used for modeling of the ten methods of radius-estimating of horizontal curve, which consist of Ball Bank Indicator, Chord Length, Compass, Lateral Acceleration, Plan Sheet, Advisory Speed Plate, Modified Yaw Rate, Field Survey, and Global Positioning System for the calculation of estimated-radius. The program output is comprehensive and easy to understand, while the program input is used friendly and provided with many graphical objects to facilitate ease of use. A case study of three examples presented to evaluate the modeled software of three horizontal curves. Two curves were located in university of Baghdad and a third curve was designed and includes also the experimental work of radius-estimating methods of horizontal curves as follow field survey, plan sheet, compass, Global Positioning System (GPS). Conclusion/Recommendations: The results that obtained of the three curves by using the radius-estimating methods include the true and estimated radius of each method. The field survey and the plan sheet method provided the most accurate result 0.8002 and 0.8660 respectively. The plan sheet method and GPS method is preferred, because plan sheets are easily accessible to these users and GPS is the accurate field method. While the compass method is not the accurate, it is easy to use, and has a low cost.
\end{abstract}

Key words: Geometric design, horizontal alignment, surveying, transportation, Global Positioning System (GPS), horizontal curves, spiral, chord length, plan sheet, compass, visual basic language, lateral acceleration, radius

\section{INTRODUCTION}

When a highway changes horizontal direction, making the point where it changes direction a point of intersection between two straight lines is not feasible. The change in direction would be too abrupt for the safety of modem, high-speed vehicles. It is therefore necessary to interpose a curve between the straight lines. The straight lines of a road are called tangents because the lines are tangent to the curves used to change direction. Horizontal curves are, in effect, transitions between two tangents. These deflection changes are necessary in virtually all highway alignments to avoid impacts on a variety of field conditions (e.g., right-of-way, natural features and manmade features) (AASHTO, 1994; Aram, 2010).

\section{MATERIALS AND METHODS}

In practically all modem highways, the curves are circular curves; that is, curves that form circular arcs. The smaller the radius of a circular curve, the sharper the curve. For modern, high-speed highways, the curves must be flat, rather than sharp. That means they must be large-radius curves (FHWA, 2003).

In highway work, the curves needed for the location or improvement of small secondary roads may be worked out in the field. Usually, the horizontal curves are computed after the route has been selected, the field surveys have been done and the survey base line and necessary topographic features have been plotted. In urban work, the curves of streets are designed as an integral part of the preliminary and final layouts, which are usually done on a topographic map.

Corresponding Author: Asma Th. Ibraheem, Department of Civil Engineering, Nahrain University, College of Engineering, Baghdad, Iraq 

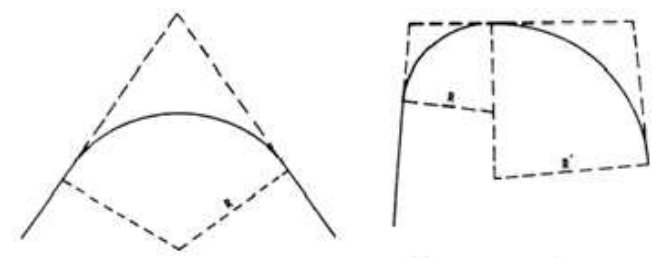

A simple curve

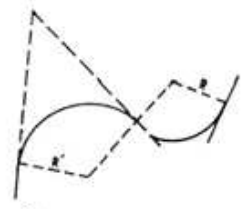

C reverse curve

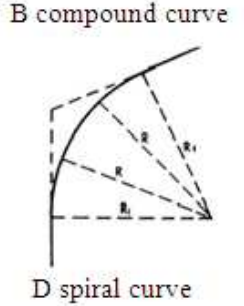

Fig. 1: Types of the horizontal curves

In highway work, the road itself is the end result and the purpose of the design. But in urban work, the streets and their curves are of secondary importance; the best use of the building sites is of primary importance (AASHTO, 1994).

Types of the horizontal curves: There are five types of horizontal curves as illustrated in Fig. 1. They are described as follows (Garber and Hoel, 2001):

Simple: The simple curve is an arc of a circle. The radius of the circle determines the sharpness or flatness of the curve.

Compound: Frequently, the terrain will require the use of the compound curve. This curve normally consists of two simple curves joined together and curving in the same direction (Garber and Hoel, 2001).

Reverse: A reverse curve consists of two simple curves joined together, but curving in opposite direction. For safety reasons, the use of this curve should be avoided when possible.

Spiral: The spiral is a curve that has a varying radius. It is used on railroads and most modem highways. Its purpose is to provide a transition from the tangent to a simple curve or between simple curves in a compound curve (Garber and Hoel, 2001).

Broken-back curves: This type of alignment should be avoided except where very unusual topographical or right-of-way conditions dictate otherwise. Highway engineers generally consider the broken-back alignment to be unpleasant and awkward and prefer spiral transitions or a compound curve alignment with continuous superelevation for such conditions.
Methods of radius-estimating of horizontal curves: Many groups, including transportation agencies, accident investigators and transportation researchers, would find an accurate, quick and safe method to estimate the radius of horizontal curves particularly useful. The radius estimating methods were as follows:

- $\quad$ Basic ball bank indicator (BBI)

- Advanced Basic ball bank indicator

- Chord length

- Compass

- Field survey

- Global Positioning System (GPS) unit

- Lateral acceleration

- Plan sheet

- Speed advisory plate and

- Vehicle yaw rate

Ball Bank Indicator (BBI) Method: A BBI is a curved level commonly used to determine the safe speed of horizontal curves. A BBI measures the combination of lateral acceleration, vehicle body roll and superelevation in the following relationship:

BBI = lateral acceleration - superelevation body roll (1)

Each term in the above equation cannot be individually determined from the BBI reading alone. The BBI reading is simply a relationship of these three components. If it were not for the body-roll angle, the BBI reading in degrees would be a direct measure of lateral acceleration. If body roll is neglected, then the radius can be estimated using the point-mass Eq:

$$
\mathrm{R}=\frac{\mathrm{V}^{2}}{127(\mathrm{e}+\mathrm{f})}
$$

Where:

$$
\begin{aligned}
\mathrm{R} & =\text { Radius }(\mathrm{ft}) \\
\mathrm{V} & =\text { Speed }(\mathrm{mph}) \\
\mathrm{E} & =\text { Average full superelevation } \\
\mathrm{F} & =\text { Side friction factor }
\end{aligned}
$$

Usually several readings are taken at different speeds until a satisfactory speed angle combination is obtained. An example of a ball-bank reading is illustrated below in Fig. 2 (Carlson and Mason, 1999).

Advanced ball bank indicator method: In this approach, the researchers hoped to improve the ball bank indicator method by measuring the body roll of the vehicle and incorporating the measurements into the radius estimation. 


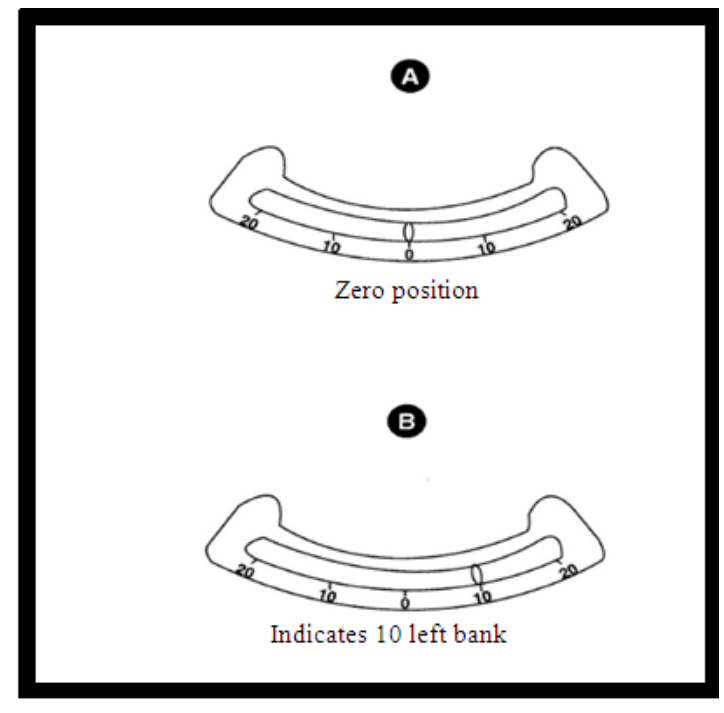

Fig. 2: Display with ball-bank indicator readings

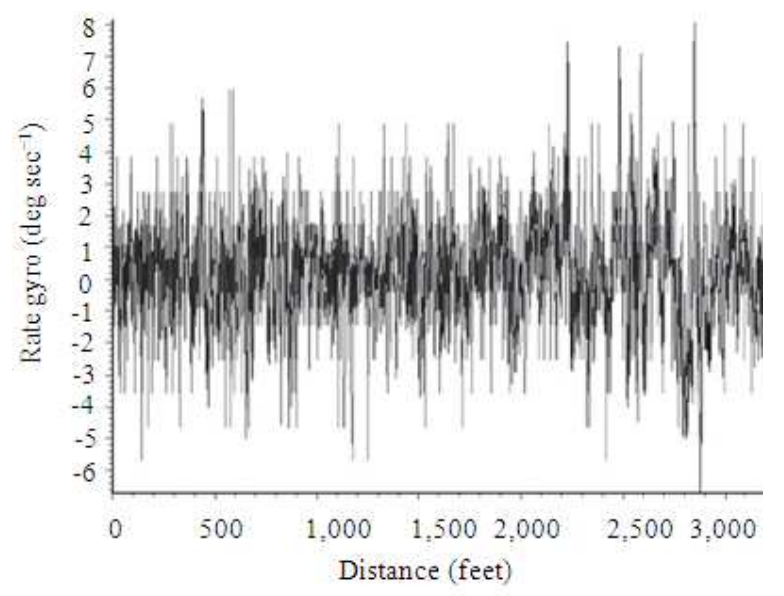

Fig. 3: Example of excess noise from roll rate sensors

To accomplish this improvement, the researchers used roll-rate sensors to measure the body roll of the vehicle's sprung mass and the roll of the vehicle's fixed suspension. In theory, a roll-rate sensor positioned in the sprung mass of the vehicle would measure the body roll of the vehicle plus the super elevation, whereas a roll-rate sensor positioned on the fixed suspension of the vehicle would measure only the super elevation. The difference of these two methods would result in the body roll. In addition, this method would alleviate the need for a field crew to leave their vehicle to measure super elevation or estimate super elevation. The added features of this method were envisioned to potentially increase accuracy and safety as compared with the ball bank indicator method (Carlson et al., 2005).
An example of data measured along one of the test curves is shown in Fig. 3.The data represent the roll rate of the sprung mass and the roll rate of the fixed suspension. These data have considerable variation, even with the data filters positioned at their maximum value. Due to this excessive noise, this method was not pursued further (Garber and Hoel, 2001).

Chord length method: A Chord Length is a line that touches the circumference of a circle at two points. With the chord method, a technician stretches a string of known length so that each end just touches the lane edge-line of the horizontal curve. It should be noted that the string can be stretched between any two points between the PC and PT of equal radii. However, both ends of the string must be within the limit of the curve. After the string is stretched, an offset distance is measured from the middle of the string to the lane edgeline. With the string length and offset known, the curve radius can be calculated by (Carlson et al., 2005):

$\mathrm{R}=\frac{\mathrm{C}^{2}+4 \mathrm{M}^{2}}{8 \mathrm{M}}$

Where:

$\mathrm{R}=\operatorname{Radius}(\mathrm{m})$

$\mathrm{C}=$ Length of string $(\mathrm{m})$

$\mathrm{M}=$ Offset distance (m)

Compass method: The compass method used the measured length of the curve and the compass heading of each tangent approach to calculate the radius of the curve. The length of the curve was considered to be the average of the lengths measured along the inside and outside lane edge-line paint stripes and the compass heading was recorded for each tangent approach of the curve as shown in Fig. 4.

The length of the curve was measured along the inner and outer edges of the road, rather than along the centerline, in an attempt to keep the researcher out of the main traffic lanes. The difference of the two compass headings was calculated in degrees and the radius of the curve was then calculated by (Carlson et al., 2005):

$\mathrm{R}=\frac{57.3 \times \mathrm{L}}{\Delta}$

Where:

$\mathrm{R}=\operatorname{Radius}(\mathrm{m})$

$\mathrm{L}=$ Length of curve $(\mathrm{m})$

$\Delta=$ Difference in compass headings (degrees) 


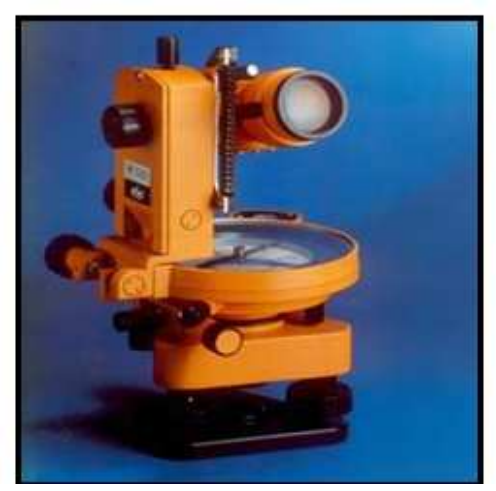

Fig. 4: Survey compass

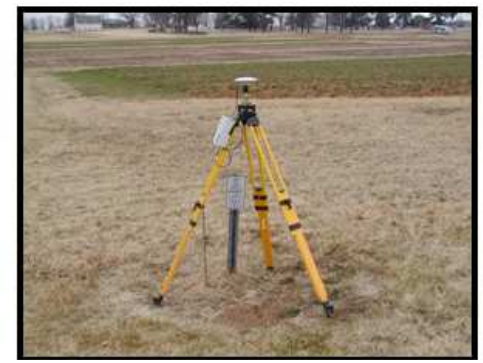

Fig. 5: Global Positioning System (GPS) unit

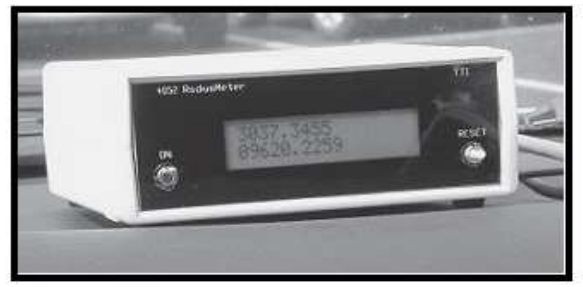

Fig. 6: Electronic display of radiusmeter (GPS method)

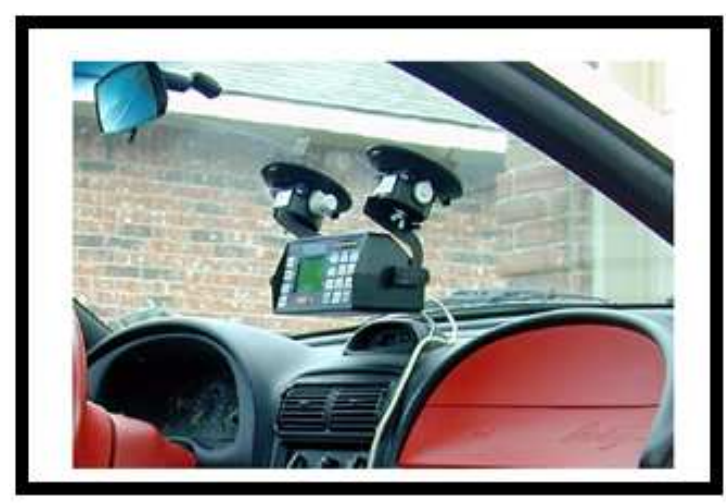

Fig. 7: Lateral accelerometer
Field survey method: A field survey of each of the selected horizontal curves was completed by using a Nikon total station. Within the boundaries of the PC and PT of the horizontal curve, at least three and up to five measurements were recorded on both the inside and outside of the curve. That is, all the recorded points were points on the circular arc, not on the adjacent tangent lines.

The survey rod was placed on the outside of the lane edge-line for the collection of all data points. The data points were recorded on the inner and outer edge of each horizontal curve in an attempt to keep the researcher out of the main traffic lanes. The actual radius of the curve was assumed to be the average of the inner and outer radii. The radius found by using this method was assumed to be the true radius and used for comparisons against the other methods (Carlson et al., 2005).

Global Positioning System (GPS) method: Advancements in GPS technology have significantly reduced the price of GPS equipment and increased its accuracy to a point that it is now a feasible option to use in making highway-related measurements Fig. 5. In concept, this method is similar to the compass method in that the curve radius can be estimated from a measured deflection angle and the corresponding curve length-information that can be acquired from typical GPS data streams (Carlson et al., 2004).

The Radiusmeter immediately processes GPS data by means of a microcontroller and solves for the radius of the curve. This system can operate from any vehicle traveling at any speed, which means that a data collection vehicle can travel along with the normal traffic flow. The display of the Radiusmeter is shown in Fig. 6.

Lateral acceleration method: The lateral acceleration methods are similar to the ball indicator methods in that the measurement is the unbalanced lateral acceleration rate, or the side friction factor. This assumes that bodyroll is neglected and super elevation is known or can be estimated. This method was tested for several reasons. First, the measurement of lateral acceleration rates is digital, precise and stored to a file every 0.01 seconds along with speed and distance. Compared to the ball bank indicator, this advantage in of itself was thought to possibly provide more accurate curve radii estimates. The other advantage is that features are available that when incorporated with the lateral acceleration device were hoped to provide profiles of the super elevation and body roll as the test vehicle traversed the test 
curves. Figure 7 shows a picture of the lateral accelerometer (Carlson et al., 2004).

This method is similar to Ball Bank Indicator Methods except that the measured lateral acceleration rate is substituted in the equation below to determine the radius:

$$
\mathrm{R}=\frac{\mathrm{V}^{2}}{127\left(\mathrm{~L}_{\mathrm{f}}+\mathrm{e}\right)}
$$

Where:

$$
\begin{aligned}
& \mathrm{R}=\text { The curve radius }(\mathrm{m}) \\
& \mathrm{V}=\text { Vehicle speed }(\mathrm{km} / \mathrm{h}) \\
& \mathrm{L}_{\mathrm{f}}=\text { Lateral force (percentage of gravity) } \\
& \mathrm{E}=\text { Superelevation, as a decimal }
\end{aligned}
$$

Plan sheet method: The plan sheet method determines the radius of a curve by using information provided on as-built plan sheets, which are accessible at local transportation offices. Plan sheets contain information such as location of PC and PT, deflection angle and tangent length for all horizontal curves. The information provided on plan sheets is usually the asbuilt information. From this information, each curve radius was calculated.

The required information found on the plan sheets was the location of the start of the curve (PC), the end of the curve (PT) and the degrees of turn of the curve $(\Delta)$. This information was input into the following curve radius-estimation equation and the radius of the curve was calculated as follows (Carlson et al., 2005):

$$
\mathrm{R}=\frac{5729.578}{100 \times\left(\frac{\Delta}{\mathrm{PT}-\mathrm{PC}}\right)}
$$

Where:

$$
\begin{aligned}
& \mathrm{R}=\text { Curve radius }(\mathrm{m}) \\
& \Delta=\text { Curve deflection angle (degrees) } \\
& \mathrm{PT}=\text { Curve point of tangent }(\mathrm{m}) \\
& \mathrm{PC}=\text { Curve point of curve }(\mathrm{m})
\end{aligned}
$$

Advisory speed plate method: Advisory speeds for curves have been determined in the field by making several trial runs through the curve at different speeds in a test-vehicle equipped with a ball-bank indicator. The ball-bank reading indicates overturning forces on the vehicle and is a combined measure of the centrifugal force, vehicle roll and super elevation. The generally accepted criteria for setting advisory speeds are ball-bank readings of $14 \mathrm{deg}$ for speeds below 20 mph, 12 deg for speeds between 20 and $35 \mathrm{mph}$ and 10 deg for speeds of $35 \mathrm{mph}$ or greater.4 These criteria are based on tests conducted in the 1930s that were intended to represent the 85-90th-percentile curve speed.5. Another method used to determine the advisory speed is using the nomograph in the Traffic Control Devices Handbook (TCDH) which utilizes the following standard curve formula:

$V^{2}=127 R(e+f)$

A friction factor of 0.16 is assumed in the nomograph that corresponds to the speed at which discomfort begins for an average rider in a 1930 vintage car. This factor may not be valid for modern vehicles. The side friction factors recommended in the design criteria of the American Association of State Highway and Transportation Officials (AASHTO) vary from 0.17 at low speed to 0.10 at the highest speed.7 However, these values also are based on tests conducted in the 1930s and represent the limit at which a rider will notice a "side pitch" and begin to feel some discomfort. The ball-bank readings of $14 \mathrm{deg} 12 \mathrm{deg}$ and $10 \mathrm{deg}$ were found in these earlier studies to correspond to side friction values of $0.21,0.18$ and 0.15 , respectively.

The friction factors used in current criteria do not reflect the maximum safe speed but rather an average comfortable speed. Modern cars on dry pavement are capable of generating friction coefficients of 0.65 and higher before skidding.8 Friction coefficients of 0.40 and higher are typical on wet pavements. Thus, a curve designed for $70 \mathrm{mph}$ could be driven well over $100 \mathrm{mph}$ before it skidded out.

Modified yaw rate method: The modified yaw rate method is a measure of the deflection angle of the curve. With the same roll rate sensors, only this time mounted in an inverted position, the deflection angle of the curve was measured as the test vehicle traversed the highway. The data acquisition unit (in this case a VC3000) simultaneously recorded the yaw rate (degrees per second) and the distance traveled along the curve. Essentially, the modified yaw rate method is an automated version of the compass method; however, the compass method required additional time and exposed the field crews to potential hazards and along the road (Carlson et al., 2005).

The lateral accelerometer also allowed the researchers to place one of the roll-rate sensors in an inverted position such that it would act as a pseudo yaw rate transducer and record the deflection of the curve while the lateral accelerometer simultaneously measured the distance traveled along the curve. 


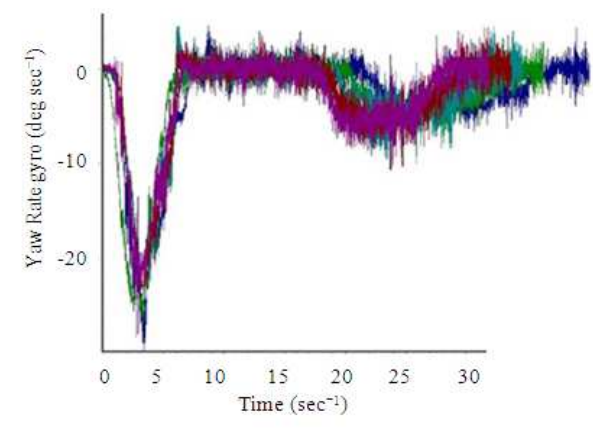

Fig. 8: Example of yaw rate data from one curve

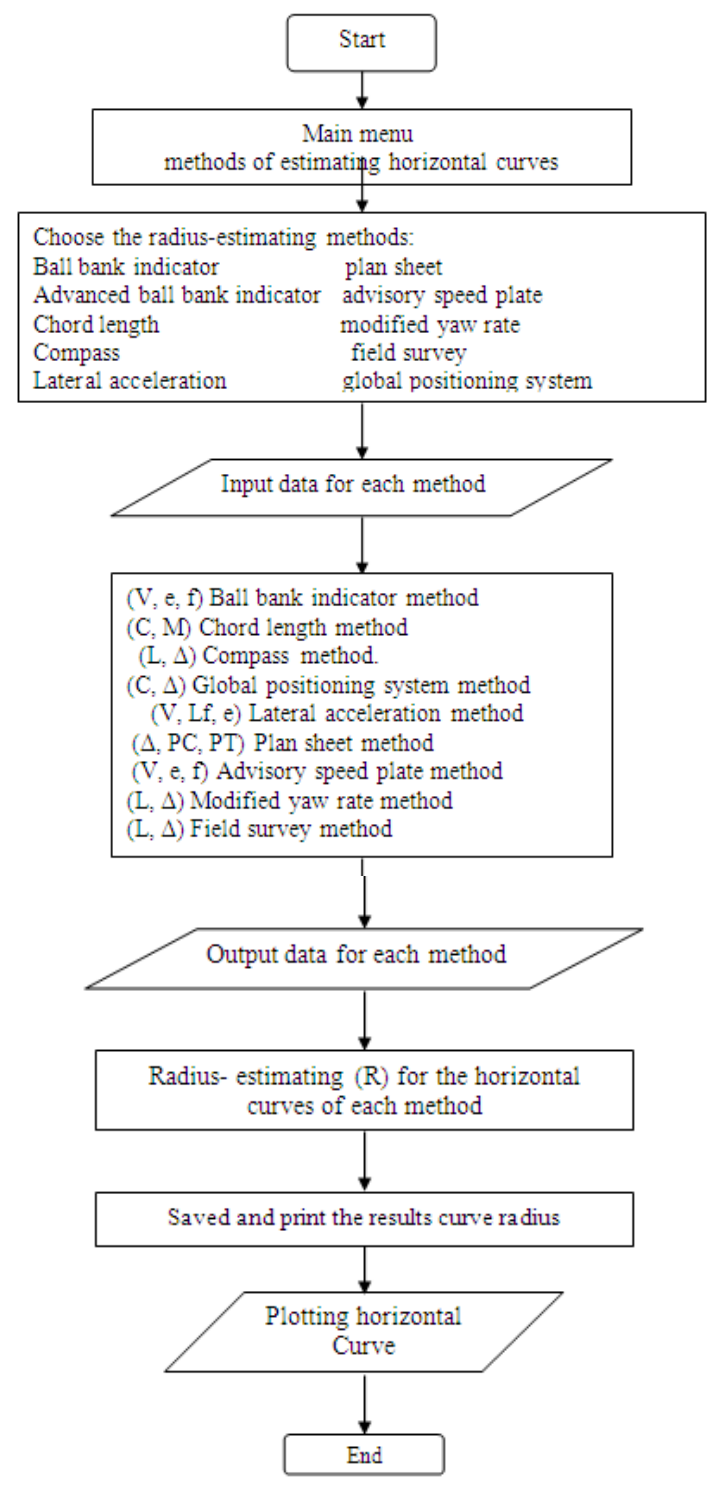

Fig. 9: Flowchart of work steps
Although the same data can be obtained by walking the curve with a handheld compass and a measuring wheel, the latter approach requires additional time and exposes the field crews to potential hazards on and along the road. The radius is then calculated using the simple Eq. (Carlson et al., 2004):

$\mathrm{R}=\frac{57.3 \times \mathrm{L}}{\Delta}$

Figure 8 shows an example of the yaw rate data collected on one test. The yaw rate was plotted versus time. There are four replicates of data, each collected while driving the same constant speed. Due to the amount of noise in the yaw rate data, this method was not pursued further.

Modeling the method so festimating techniques of horizontal curves: The radius-estimating for horizontal curve are modeled by using Visual Basic language which is called HCRET (Horizontal Curve Radius Estimating Techniques). The program is formulated and written by using Visual Basic, Version 6. This version of the language is objecting oriented provided with comprehensive tools to simplify the task of programming and to provide the programmer with wide range of options for design of the user interface system. Figure 9 shows the flowchart of this software.

The input data for each one of these forms and the link between these forms are described in the following steps with the aid of flowcharts, which provide description for the logic and the steps followed in the development of the program.

Program menus and input forms: In Visual Basic programming the term FORM is usually used to refer to the graphical area appeared on the screen, which is used to hold objects that may be fields or tables containing values, graphics or text boxes for input the required data values. The form interface is used because most people are familiar with study form. These forms are written in such away to be are user friendly and allow the data input to the program interactively. When the program (HCRET) is run, the user presented with the form shown in Fig. 10.

This form displays program name and version, if the user select "start" button the main program menu interface displayed on the screen.

The main Form of (HCRET) contains the methods of estimating of horizontal curves. As shown in Fig. 11. The methods of estimating of the radius of the horizontal curves classified into ten methods (Ball Bank Indicator, Advanced Ball Bank Indicator, Chord Length, Compass, Field Survey, Global positioning System, Lateral Acceleration, Plan Sheet, Advisory speed plate and Modified Yaw Rate). 


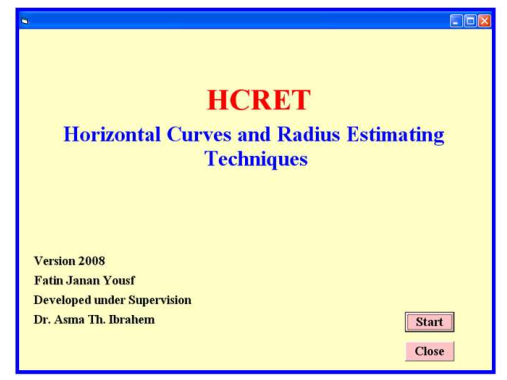

Fig. 10: Program interface

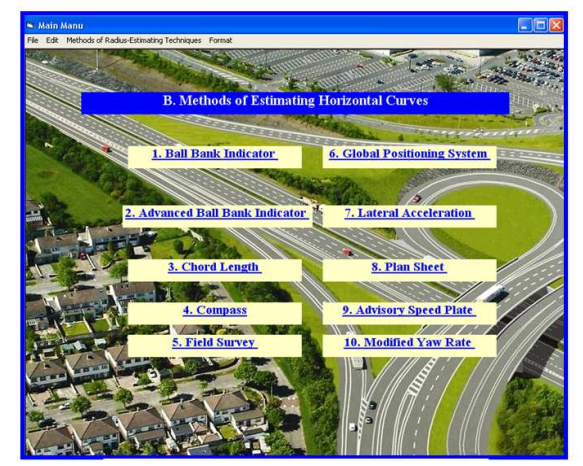

Fig. 11: The main page of (HCRET)

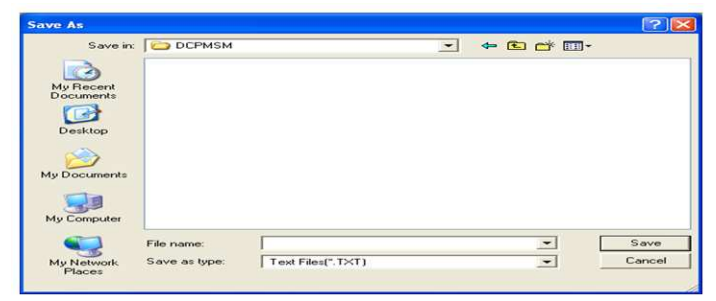

Fig. 12: Open file dialog box

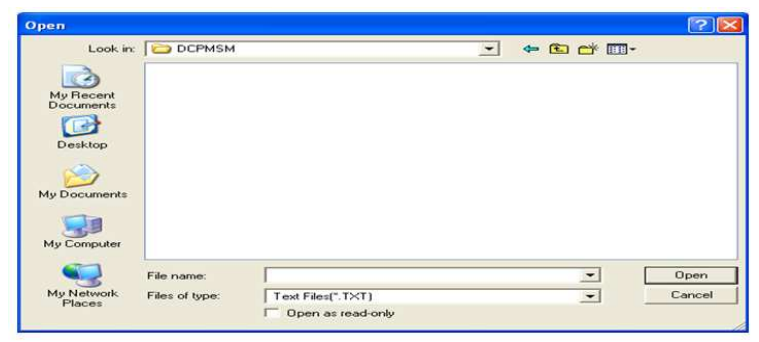

Fig. 13: Save file dialog box

File menu: The menu items available under the file menu are open, save as, save, close, print and exit:

- When "Open" is selected, an existing design text file can be selected to open and made available to the user for seeing the calculated results or edit an existing file as shown in Fig. 12
- When "Save As" is selected, a new file is created. The current file is then copied to the new file on the disk or location specified by the user

- When "Save" is selected, an edited open file can be saved at any existing disk drive as shown in Fig. 13

- When "Close" is selected, to close opened text file.

- When "Print" is selected, to print text file

- When "Exit" is selected, the program terminates and the user is returned to the operating system level

Radius-estimating techniques menu: Radiusestimating techniques of the horizontal curves are described completely in chapter four. The radiusestimating techniques menu consists of the following:

- Ball Bank Indicator Method

- Advanced Basic ball bank indicator Method

- Chord Length Method

- Compass Method

- Lateral Acceleration Method

- Plan Sheet Method

- Advisory speed plate Method

- Modified Yaw Rate Method

- Field Survey Method

- Global Positioning System (GPS) Method

Ball bank indicator method: When the user selects this option, the form shown in Fig. 11 is displayed on the screen the user has to input the following data:

- Lateral acceleration

- Body roll

- Ball Bank Indicator (BBI)

- Vehicle speed (V)

- $\quad$ Side friction Factor (f)

When these data are input, the computer program starts the required calculation and computes average full superelevation and curve radius as shown in Fig. 14. The program output is saved for later use by the user in a text file. After designing of Ball bank indicator method, the program enables the user to move to the next method in the Radius-estimating techniques from the main menu of the developed program.

Chord length method: When this option is selected, the form shown in Fig. 11 is displayed on the screen. The input data for this option as shown in these figures are:

- $\quad$ Length of string $(\mathrm{C})$

- Offset distance (M) 


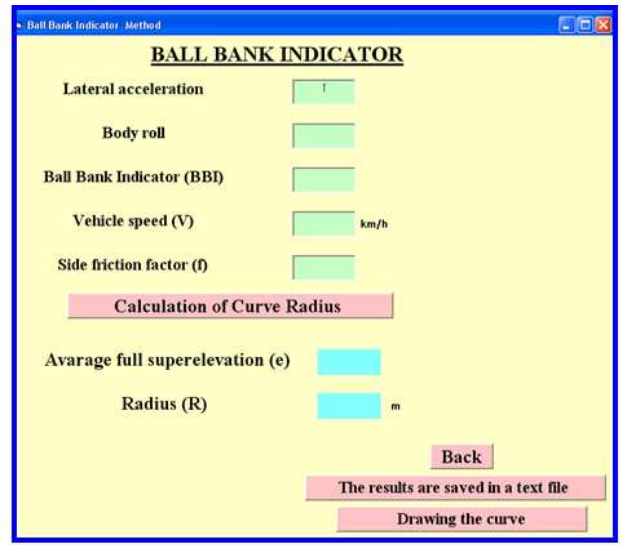

Fig. 14: Ball bank indicator method, input and computation

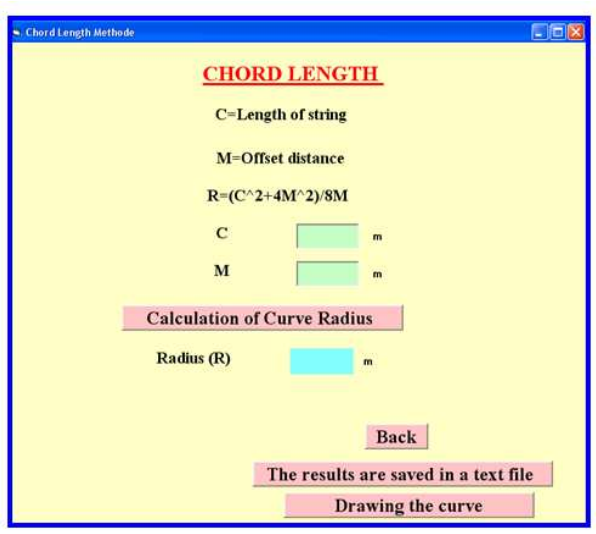

Fig. 15: Chord length method, input and computation

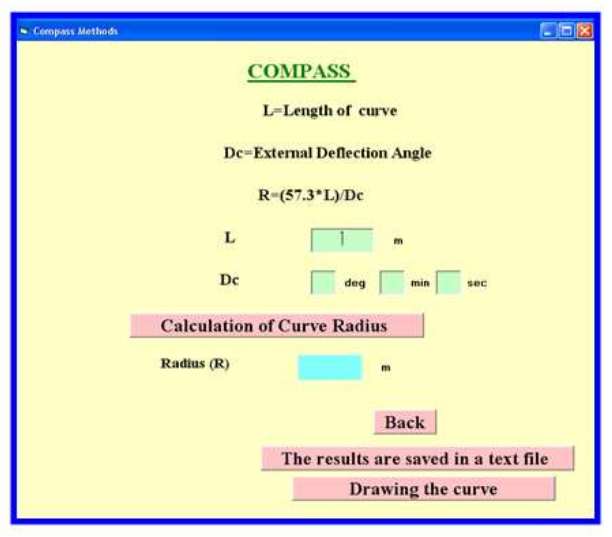

Fig. 16: Compass method, input and computation

Following the end of data input, the program calculates the curve radius. When these data are input, the computer program starts the required calculation and computes average full superelevation and curve radius as shown in Fig. 15. The program output is saved for later use by the user in a text file. The program output is saved for later use by the user in a text file. After designing of chord length method, the program enables the user to move to the next method in the Radius-estimating techniques from the main menu of the developed program.

Compass method: When this option is selected the Fig. 11 shown presented to the user. The user has to input the following information:

- Length of curve (L)

- External Deflection Angle $(\Delta)$

Following the data input stage; the computer program calculates the curve radius as shown in Fig. 16. The program output is saved for later use by the user in a text file. After designing of compass method, the program enables the user to move to the next method in the Radius-estimating techniques from the main menu of the developed program.

Lateral acceleration method: When the user selects this option the form shown in Fig. 11 is displayed on the screen the user has to input the following data:

- $\quad$ Vehicle speed (V)

- Lateral force (Lf)

- Super elevation (e)

When these data are input, the computer program starts the required calculation and computes curve radius as shown in Fig. 17. The program output is saved for later use by the user in a text file. After designing of lateral acceleration method; the program enables the user to move to the next method in the Radiusestimating techniques from the main menu of the developed program.

Plan sheet method: When this option is selected, the form shown in Fig. 11 is displayed on the screen. The input data for this option as shown in these figures are:

- External Deflection Angle $(\Delta)$

- Curve point of tangent (PT)

- Curve point of curve (PC) 


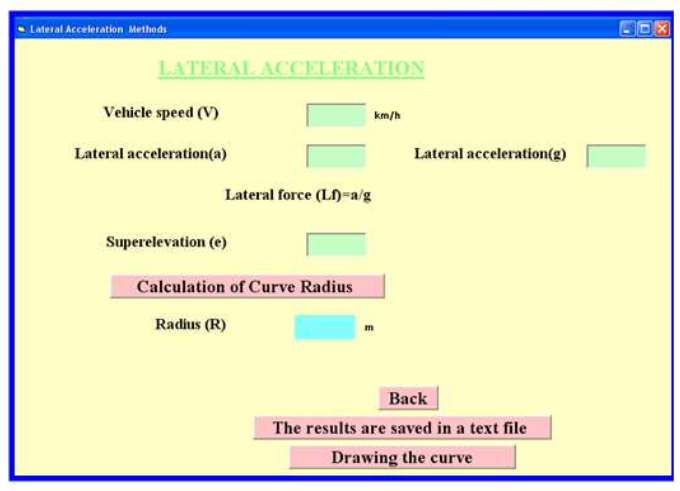

Fig. 17: Lateral acceleration method, input and computation.

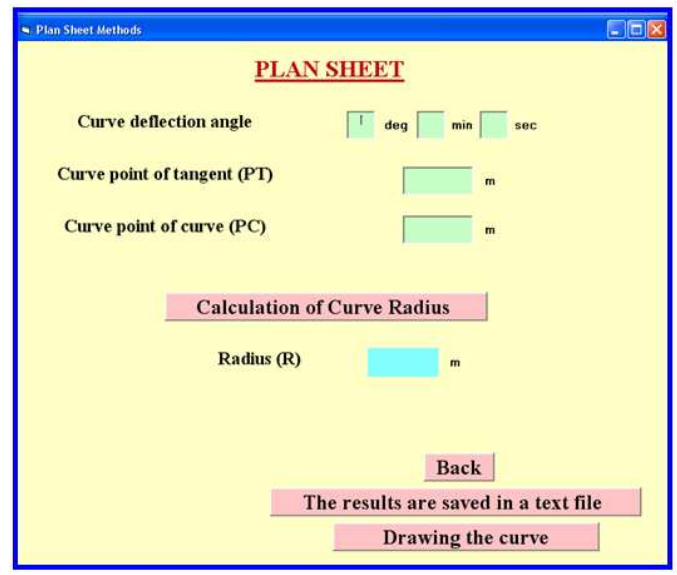

Fig. 18: Plan sheet method, input and computation

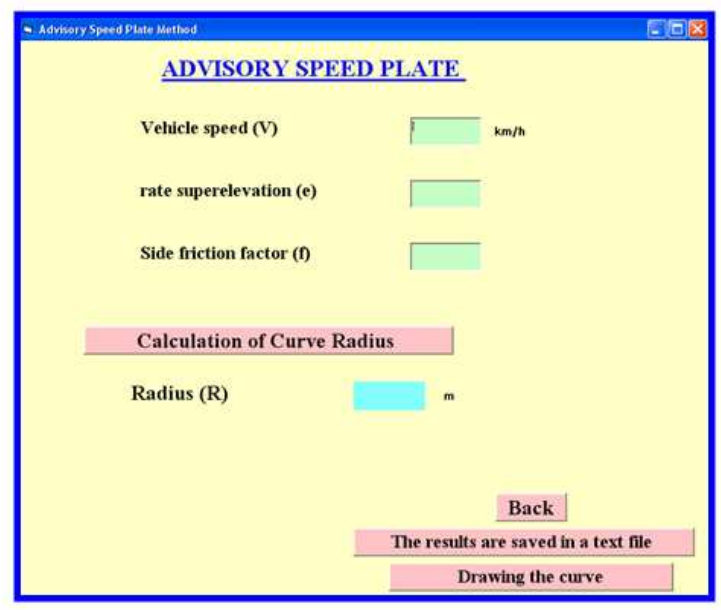

Fig. 19: Advisory speed plate method, input and computation
Following the end of data input, the program calculates the curve radius as shown in Fig. 18. The program output is saved for later use by the user in a text file.

After designing of plan sheet method, the program enables the user to move to the next method in the Radius-estimating techniques from the main menu of the developed program.

Advisory speed plate method: When the user selects this option the form shown in Fig. 11 is displayed on the screen the user has to input the following data:

- $\quad$ Vehicle speed (V)

- Rate of super elevation (e)

- $\quad$ Side friction factor (f)

When these data are input, the computer program starts the required calculation and computes curve radius as shown in Fig. 19. The program output is saved for later use by the user in a text file.

After designing of Advisory speed plate Method, the program enables the user to move to the next method in the Radius-estimating techniques from the main menu of the developed program.

Modified yaw rate method: When this option is selected, the figure shown in 11 presented to the user. The user has to input the following information:

- Length of curve (L)

- External Deflection Angle $(\Delta)$

Following the data input stage; the computer program calculates the curve radius as shown in Fig. 20. The program output is saved for later use by the user in a text file.

After designing of modified yaw rate method, the program enables the user to move to the next method in the Radius-estimating techniques from the main menu of the developed program.

Field survey method: When this option is selected the figure shown in 11 presented to the user. The user has to input the following information:

- Length of curve (L)

- External Deflection Angle $(\Delta)$

Following the data input stage; the computer program calculates the curve radius shown in Fig. 21. The program output is saved for later use by the user in a text file. 
Am. J. Engg. \& Applied Sci., 4 (2): 276-287, 2011

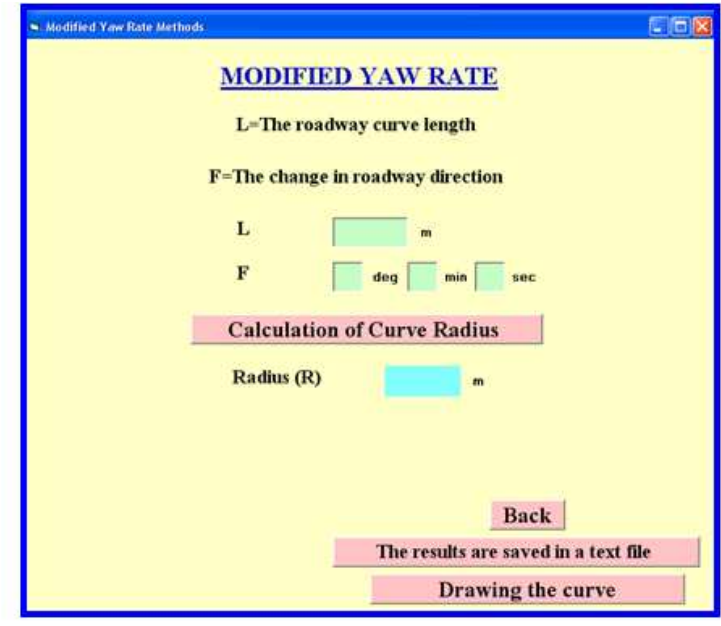

Fig. 20: Modified yaw rate method, input and computation

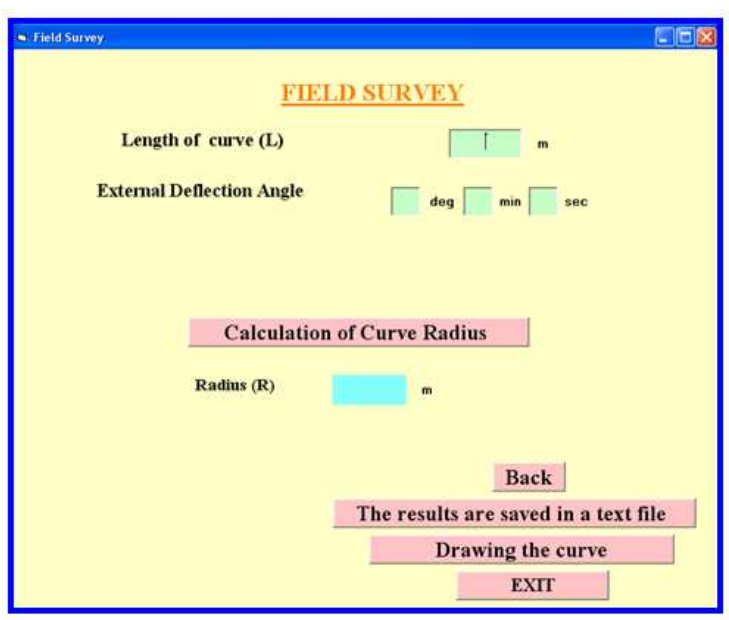

Fig. 21: Field survey method, input and computation

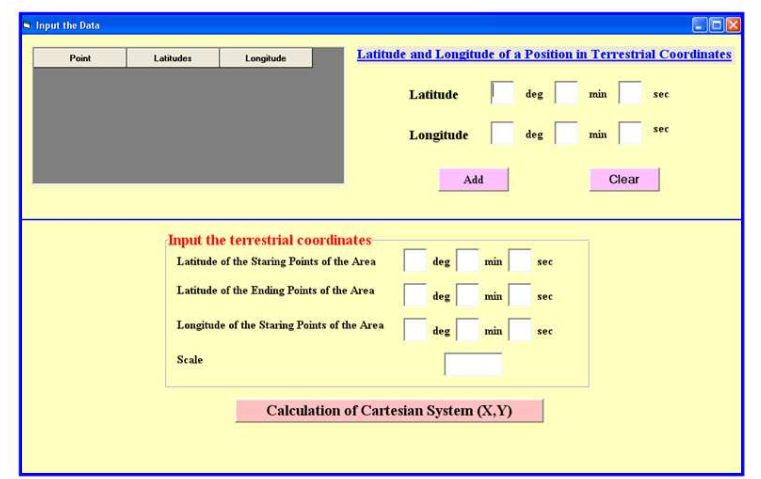

Fig. 22: Inputs data

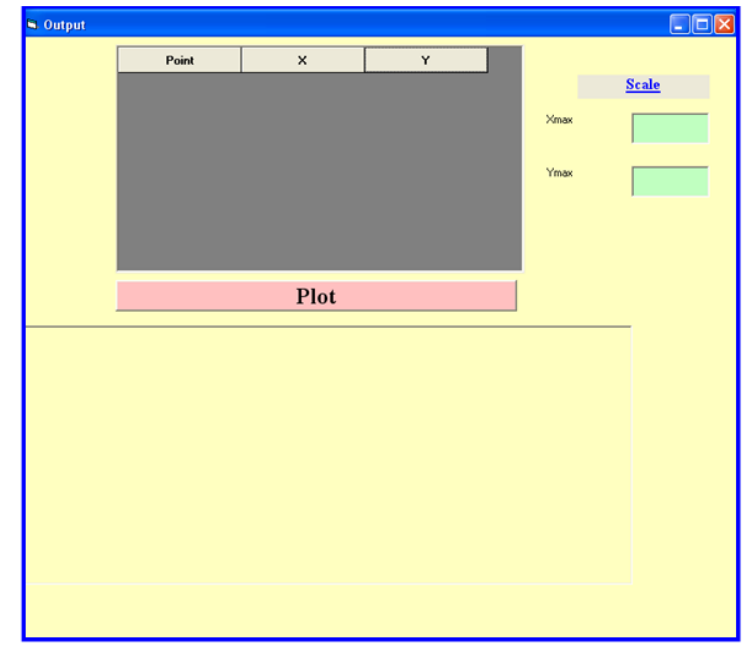

Fig. 23: Output of the Cartesian coordinates

After designing of field survey method, the program enable the user to move to the next method in the Radius-estimating techniques from the main menu of the developed program or can exit the radius-estimating techniques if it the last method.

Global Positioning System (GPS) method: When this option is selected the figure shown in 22 presented to the user. The user has to input the following information:

- Latitude and Longitude of a Position in Terrestrial Coordinates of the number from the points $(\lambda, \varphi)$ to transform to the Cartesian system (x, y)

- Latitude of the Staring Points of the Area $\left(\varphi_{1}\right)$

- Latitude of the Ending Points of the Area $\left(\varphi_{2}\right)$

- Longitude of the Staring Points of the Area $\left(\varphi_{3}\right)$

- Scale (S)

When these data are input the computer program starts the computation of the Cartesian coordinates for the all points $(\mathrm{x}, \mathrm{y})$ and when the user selects "plot" button, the plotting of the curve illustrated will be start as Fig. 23.

Plotting of the horizontal curves: All radiusestimating methods can draw the curve. Therefore, if the user selects the option of drawing the curve the window shown in Fig. 24 displayed on the screen. The user has to input the following data: 
Am. J. Engg. \& Applied Sci., 4 (2): 276-287, 2011

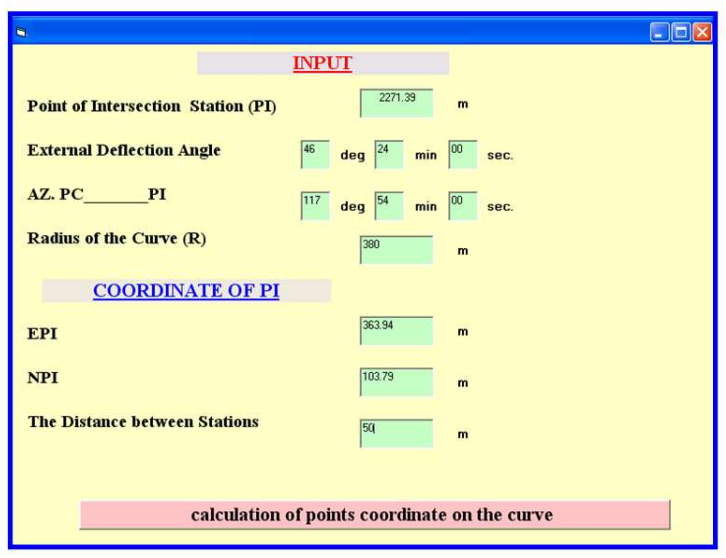

Fig. 24: Inputs drawing curve

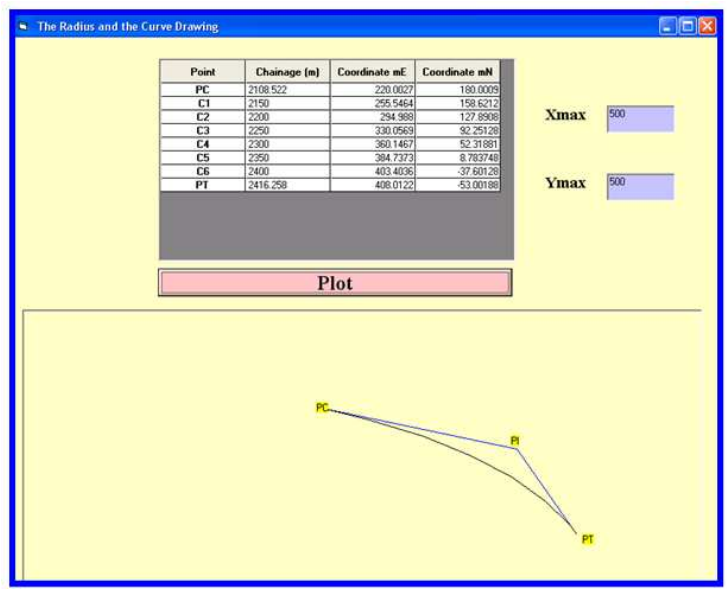

Fig. 25: The result and curve drawing

- Point of Intersection Station (PI)

- The External Deflection Angle $(\Delta)$

- The Azimuth between PC and PI

- The Coordinates of the PI (EPI, NPI)

- Radius of the curve (R)

- The Distance between Stations

When these data are input the computer program and when the user selects "plotting " button to begin by drawing the curve are illustrated in the below Fig. 25 .

\section{RESULTS AND DISCUSSION}

Factors considered included accuracy and, ease of use for identify and assess radius-estimating methods. The three methods were evaluated to determine their advantages and disadvantages when surveying a horizontal curve.
Table 1: The final results

\begin{tabular}{lllll}
\hline Methods & $\begin{array}{c}\text { Curve } \\
\text { no. }\end{array}$ & $\begin{array}{l}\text { True } \\
\text { Radius } \\
(\mathrm{m})\end{array}$ & $\begin{array}{l}\text { Estimated } \\
\text { Radius(m) }\end{array}$ & $\begin{array}{l}\text { Standard } \\
\text { Deviation } \\
(\mathrm{m})\end{array}$ \\
\hline Field Survey & 1 & 126 & 127.029 & \\
& 2 & 162 & 162.689 & 0.8002 \\
Plane Table & 3 & 100 & 99.5044 & \\
& 1 & 126 & 127.5 & \\
& 2 & 162 & 162 & 0.866 \\
Compass & 3 & 100 & 100 & \\
& 1 & 126 & 127.381 & 1.2206 \\
GPS & 3 & 162 & 162.956 & \\
\hline & 3 & 100 & 99.0867 & - \\
\hline
\end{tabular}

Accuracy: The Table 1 represents the results that obtained of the three curves by using the radiusestimating methods are as follow.

From a practical point of view, the field survey and the plane sheet method provided the smallest accurate results 0.8002 and 0.8660 , respectively.

Ease of use: Ease of use is important in eliminating user error. The following discussion provides the experience gained during this study. The field survey method requires that users undergo a significant amount of training before they can measure the radius of a curve. Sophisticated total stations can be overwhelming for the untrained. It is probably the most difficult of all the methods to implement.

The compass method is easy to use, although aligning the compass needle along the tangents to get the bearing of the approaching and departing tangents can be challenging.

The plane table method is also easy to use, where; all plotting is done in the field and checks on the location of the plotted points are obtained readily. Although the plane-table and accessories are cumbersome and the time required in the field is relatively large.

The GPS method requires no calibration or external peripherals. The equipment has an activator button, a magnetic antenna and a small box with an LCD screen. Little training is needed to use the system and it can be easily moved from one place to another.

\section{CONCLUSION}

From the results obtained in research, the following conclusions can be made:

- The developed program is modeled by using VBASIC Language as a software name Radius Estimating Techniques (RET). The (RET) contains (16) forms, each one include the input and the computation of radius-estimating methods for horizontal curves 
- The developed program (RET) needs less time as compared to the manual method in order to solve for the problem

- Three horizontal curves (two selected curves and one designed) are taken to evaluate the (RET) program

- The results of the estimated radius of these three curves show a good agreement with that true radius. The field survey and the plan sheet method provided the most accurate result 0.8002 and 0.8660 respectively

- The precision of some methods was affected by the length of the radius. The only two methods that were not affected by the length of the radius were the plan sheet method and the GPS method

- The plan sheet method is preferred, because plan sheets are easily accessible to these users

- GPS is also a preferred method. It is the most accurate and precise field method and it is easy to implement using a device in the radius-meter

- Although the compass method is not the most accurate precise, it is easy to use has a low cost

\section{REFERENCES}

AASHTO, 1994. A Policy on Geometric Design of Highways and Streets. American Association of State Highway and Trans, Washington, DC., ISBN-10: 1560510684, pp: 1052.
AAram, A., 2010. Effective safety factors on horizontal curves of two-lane highways. J. Applied Sci., 10: 2814-2822.

http://www.doaj.org/doaj?func=abstract\&id=662772

Carlson P.J, M. Burris, K. Black and E.R. Rose, 2005. Comparison of radius-estimating techniques for horizontal curve. J. Transportation Res. Board, 7683. http://pubsindex.trb.org/view.aspx?id=772013

Carlson, P.J and J.M. Mason, 1999. Relationships between ball bank indicator readings, lateral acceleration rates and vehicular body-roll rates. J. Transportation Res. Board, 34-42. http://pubsindex.trb.org/view.aspx?id=506960

Carlson, P.J., E.R. Rose, S.T. Chrysler and A.L. Bischoff, 2004. Simplifying delineator and chevron applications for horizontal curves. Report number FHWA/TX-04/0-4052-1, Texas Transportation Institute, College Station. http://tti.tamu.edu/documents/0-4052-1.pdf

FHWA, 2003. Manual on uniform traffic control devices for streets and highways. Department of Transportation, U.S. http://mutcd.fhwa.dot.gov/

Garber, N.J. and L.A. Hoel, 200. Traffic and Highway Engineering. 3rd Edn., CL-Engineering, ISBN-10: 0534387438, pp: 1040. 